\title{
Prevalence of Cancer in District Banu khyber pakhtunkhwa, Pakistan
}

${ }^{1}$ Hina Rehman, University of malakand, Chakdara Dir Lower. hina.rehman@uom.edu.pk ${ }^{2}$ Muhammad Ilyas, Universite Paris-Est Creteil, France. Muhammad.ilyas@u-pec.fr

${ }^{2}$ Muzamil Shah, Quaid-i-Azam University Islamabad. muzamilshah1989@gmail.com

${ }^{1}$ Waqar Ali, Assistant Professor, University of malakand, Chakdara Dir Lower. waqarali@uom.edu.pk

${ }^{1}$ Ayaz Ali Khan, Assistant Professor, University of malakand, Chakdara Dir Lower. ayazkhan@uom.edu.pk

\begin{abstract}
Present study was designed to check prevalence of cancer in residents of District Bannu, Khyber Pakhtunkhwa. Patients data were collected from three consulted Institutes during year 2005-09. The data was analyzed for different parameters; year wise, age wise prevalence, gender wise, occupation wise and marital status wise prevalence, addiction status, type of cancer, site affected, diagnostic tests performed and treatment of cancer. Results revealed that during 2005, a high number of cancer patients were present. A total of 172 patients were in the age group of 51-60 years, while only 11 patients were in age group of 80 plus year. Female patients were more as compared to male. Married people were highly affected than unmarried. Patients addicted to smoking were highly affected than non-addicted patients. Malignancy was high in patients as compared to benign cancer. The most affected site was blood system. The most affected people occupation wise were house wives followed by farmer. Biopsy was mostly conducted for diagnosis of cancer. Most of the patients were treated with chemotherapeutic agents. It has been revealed that the number of cancer patients decreased per annum. Moreover, the study should be conducted on general population of Bannu as well as of the Khyber PakhtunKhwa to sort out the total number of patients. Government should launch preventive, diagnostic programs so that prevalence may be minimized.
\end{abstract}

Key words: Cancer, Bannu, Prevalence, Khyber Pakhtunkhwa

\section{Introduction}

Cancer origin is accredited to the Greek physician hippocrates (460-370 B.Cs), who was deliberated "Father of Medicine." Hippocrates used the words carcinos and carcinoma to 
define the ulcer-forming and nonulcer forming tumors (Kardinal and Yarbo, 1979). Cancer is a disease that result from the changes in the cellular behavior due to changes in the genetic material of the cells; as a result cancer cause proliferate in uncontrolled manner forming malignant tumor that tend to grow in an invasive manner, destroying the normal tissue in which they appear (Karp, 1996). In all over the world, cancer is becoming a serious health hazard causing about $12 \%$ of deaths and mainly in Asian Pacific countries, it has become the leading cause of death.

Different (200) types of cancer that can occur anywhere in the body having different symptoms, causes which require different treatments. Cancers are classified according to the tissue and cell type from which they arise. About $90 \%$ of cancers are Carcinomas, those types of tumors that rise in the body's organs tissues. Next to carcinoma, Sarcomas cancers are initiates in muscles, bone, fibrous tissue or fat and cartilage. One type of cancer is Leukemia's, a cancer of blood or their forming organs (Kumar et al., 1989; Doll, 1987; Oldham, 1987).

In Pakistan, the common reported male cancer are lungs and oral cancers and female cancers are breast and cervical (Baig and Ali, 2006). In the children of Khyber Pakhtunkhwa, reported cancer types are lymphoid and myeloid leukemia, central nervous system cancer (CNS), bone tumors, soft tissue sarcoma, neuroblastoma and cancer of testicular (Khan et al., 1997).

Prevalence of a disease is clearly an important measure of burden, since describe the new cases that will require medical attention. It is the key measure when considering prevention. Measurement of prevalence requires the identification of all new cases of disease in a define population through some kind of case-finding mechanism, with record-linkage to ensure that persons are not confused with events. This is the function of the populationbased cancer registry. Cancer registries may present prevalence according to histological sub type of cancer, or stage of disease at diagnosis ( $\mathrm{Ng}$ et al., 2001). Cancer prevalence data is available in the form of hospital and departmental based records in twenty-six cancer centers in the country (Javed, 2006). Exact prevalence in Pakistan is not known but ovarian cancer is the fourth most common cancer among females of Pakistan and continues to present at an advanced stage (Parveen et al., 1999).

To collect the cancer data, different methods are used in which cancer registry is compulsory. One of the best methods is the cancer registry which is based on population. The other method is an institution/hospital-based registry of cancer, a significant process delivers useful evidence to researcher and doctors in different cancer treatment (Gress, 2002). Pakistan has a high prevalence of cancer, from its independence in 1947 to the present (Abbas, 2003). Different cancer registries are working in the country to diagnose and provide possible treatment. The data is compared to obtain a net national cancer registration; for example, the differences in the prevalence of cancer in Karachi and Quetta have been studied (Bhurgri et al., 2003). In the scenario of limited resources for implementation of screening programs in Pakistan, the only practical option for early 
detection is through mass education about cancers, their risk factors, screening modalities and presentation symptoms (Khan et al., 2006). Regular screening examination by health care professional can result in the detection of cancer of the breast colon, rectum, cervix, prostate, testis, oral cavity and skin at earlier stages when treatment is more likely to be successful (Cancer Facts and Figures, 2003). Blood tests, Ultrasound and Computerized tomography (CT scan) (Takalkar et al., 2008), Biopsy (Apantaku, 2000), Magnetic Resonance Imaging (MRI) (Elmore et al., 2005). Advances in cancer therapy are made by continual investigation and evaluation of treatment results and their incorporation in the practice of oncology (Miller et al., 1981). Chemotherapy (Karnofsky, 2010) Radiotherapy, or radiation therapy (International Atomic Energy Agency, 2003), large doses of androgenic, estrogenic and adrenal-cortical hormones (Karnofsky, 2010) and surgery (Javed, 2006; Rojas, 2002) are used for the treatment of cancer.

Objective of the present study was to check the Institutional/ Hospital based cancer prevalence and occurrence rate of different types of cancer in people of district Bannu, Khyber Pakhtunkhwa from 2005 to 2009. The results of the study were focused to get the information of the most infected location, age, gender, marital status, addiction, types of cancer, and test performed for diagnosis of different types of cancer. Also give awareness and proper recommendation to public health regarding cancer so that they may launch certain projects in correlation with the cancer registry centers for proper diagnosis (in time) treatment and also for prevention.

\section{Materials and Methods}

The area chosen for this study was district Bannu of Dera Ismail Khan Division Khyber Pukhtunkhawa. Patient's data was collected through a printed Questionnaire. The questions included in the questionnaire were age of the patient, gender, marital status, occupation, address, and diagnostic procedure of cancer, age of diagnosis, types of cancer, site affected and treatment. The data was collected from the files or computerized hospital cancer registry of every patient that was present in Institute of Radiotherapy and Nuclear Medicine (IRNUM) Peshawar, Shukat Khanum Memorial Cancer Hospital and Research Center (SKMCH\&RC) Lahore and Nuclear Medicine Oncology and Radiotherapy Institute (NORI) Islamabad. The records files were searched in hospitals during June-July 2010 for the prevalence of cancer of District Dir from January 2004 to December 2009. Data were analyzed by using Statistical Package for Social Science (SPSS) and arranged according to the parameters; year wise cancer prevalence rate, year wise cancer prevalence, gender wise, year wise male and female, age wise, marital status wise affected site wise, types wise, addiction wise, performed tests wise prevalence. The year wise prevalence rate was determined by using the following formula;

Prevalence rate $=($ new cancer $/$ Population $) \times 100,000$ 
The data is collected according to the following protocol under reference number ref/01/00266MM:

Age wise cancer incidence

Age wise cancer incidence was calculated by dividing different age groups. These age groups were 0-10, 11-20, 21-30, 31-40, 41-50, 51-60, 61-70, 71-80, and 81-90. Percentage for each age group was determined in total population.

\section{Gender wise cancer incidence}

The gender wise cancer incidence, male and female.

\section{Site wise cancer incidence}

Cancer types were distributed into primary Malignent sites.

\section{Cancer incidence based on marital status}

Cancer incidence based on marital status divided into married and unmarried.

\section{Cancer incidence based on different types}

Cancer incidence based on different types that is Benign and Malignant.

The data has been presented in the form of tables and graphs in result.

Also on treatment wise, tests wise.

The questionnaire has been given as under:

INTERVIEW SCHEDULE/CLINICAL RECORD FORM

1. Personnel Information:

\begin{tabular}{|l|l|l|}
\hline S. No. & Particulars & Answer \\
\hline 1 & Name & \\
\hline 2 & Age (Years) & \\
\hline 3 & Gender & Male/Female \\
\hline 4 & Marital Status & Single/Married \\
\hline 5 & Education & Literate/Illiterate \\
\hline 6 & Occupation & \\
\hline 7 & Economic status & \\
\hline 8 & Address (If willing) & \\
& & \\
\hline
\end{tabular}

2. Clinical History:

\begin{tabular}{|l|l|l|l|}
\hline S. No. & Particulars & Answers & \\
\hline 1 & Age at which cancer diagnosed & & \\
\hline
\end{tabular}




\begin{tabular}{|c|c|c|c|}
\hline 2 & Type of Cancer & Benign/Malignant & \\
\hline 3 & Effected site & & \\
\hline 4 & Blood Transfusion & Yes/No & \\
\hline 5 & Presence of Hepatitis & Yes/No & $\begin{array}{l}\text { If yes, then which } \\
\text { type, } \\
\text { *Hepatitis A } \\
\text { *Hepatitis B } \\
\text { *Hepatitis C } \\
\text { *Hepatitis D } \\
\text { *Hepatitis E }\end{array}$ \\
\hline 6 & Addiction & Yes/No & $\begin{array}{l}\text { If yes, then to which } \\
\text { narcotics } \\
* \text { Smoking } \\
\text { *Snuff } \\
\text { *Alcohol }\end{array}$ \\
\hline 7 & Test performed & Yes/No & $\begin{array}{l}\text { If yes, then which type } \\
\text { *Biopsy } \\
\text { *Endoscopy } \\
\text { *X Ray } \\
\text { *CAT Scan } \\
\text { *MRI } \\
\text { *Blood Test }\end{array}$ \\
\hline
\end{tabular}

3. History of Medication/Treatment:

\begin{tabular}{|c|c|c|c|}
\hline S. No. & Particulars & Answer & \\
\hline 1. & Initiation date of treatment & & \\
\hline 2. & Type of Treatment & Yes/No & $\begin{array}{l}\text { If yes, then what type of treatment } \\
* \text { Radiotherapy } \\
* \text { Chemotherapy } \\
\text { *Endocrine therapy } \\
\text { *Local treatment }\end{array}$ \\
\hline 3. & Prognosis & Poor/Good & \\
\hline 4. & Hospitalization & Yes/No & \\
\hline 5. & Follow up & Yes/No & $\begin{array}{l}\text { If no, what is the reason } \\
* \text { Live } \\
\text { *Dead }\end{array}$ \\
\hline
\end{tabular}

\section{Results}


During the period from 2005 to 2009 , total 780 cancer patients were registered from district Bannu, out of which 30 were registered from NORI, 665 and 85 were from IRNUM and SKMCH \& RC respectively. The following parameters were analyzed from the data obtained from these 3 institutes.

\section{Year wise cancer prevalence rate:}

Prevalence rate is calculated as the new cases of a disease during a specific time period in a population and the percentage of those numbers of people. It describes the frequency with which cases are identified. It is commonly measured in new cases per 100,000 of populations at risk and defines specific disease developing probability. Moreover high prevalence indicates high disease occurrence and vice versa. Combine data analysis regarding cancer prevalence rate in district Bannu from the three institutes (NORI, IRNUM and SKMCH \& RC) showed that during the year 2005, 2006, 2007, 2008 and 2009 total $223,72,161,169$ and 159 patients registered having prevalence rate 10.97, 3.54, 7.72, 8.32 and 7.82 per 100,000 respectively. Total incidence rate was 38.38. High and low prevalence rate was recorded in 2005 (10.97) and in 2006 (3.54) respectively. Average prevalence of cancer per year was 7.68 per 100,000 of population. Data regarding prevalence rate as a whole is given in table 01 .

Table No. 1: Year wise cancer prevalence in district Bannu from year 2005-2009

\begin{tabular}{|c|c|c|c|}
\hline S. No & Year & No of patient & Incidence rate* \\
\hline 1 & 2005 & 223 & 10.97 \\
\hline 2 & 2006 & 72 & 3.54 \\
\hline 3 & 2007 & 161 & 7.72 \\
\hline 4 & 2008 & 169 & 8.32 \\
\hline 5 & 2009 & 159 & 7.82 \\
\hline & Total & $\mathbf{7 8 0}$ & $\mathbf{7 . 7 6}^{* *}$ \\
\hline
\end{tabular}

*Incidence rate was calculated as per 100,000

** Average incidence per year

\section{Age wise prevalence:}

The collected data from three institutes was evaluated for age wise comparison and patient's data were divided into 9 different age groups. These groups from 0-10, 11-20, 21 $30,31-40,41-50,51-60,61-70,71-80$ and 80 plus. From these data it has been concluded that mostly affected patients were that of age group of 51-60 years having $172(22.05 \%)$ patients. The second mostly affected patients were age group of 41-50 years having 152 (19.48\%) patients followed by patients of age group 61-70 years having 104 (13.33\%) patients, age group 31-40 years having 94 (12.05\%) patients. After these groups 79 $(10.12 \%)$ patients were affected in age group of 21-30 years, $71(9.10 \%)$ patients were 
affected in age group of 11-20 years, 69 (8.84\%) patients were in age group of 0-10 years. The patients were less affected in age group of 70-80 years and 80 plus having $28(3.58 \%)$ and $11(1.14 \%)$ respectively as shown in figure No. 01 (attached as supplementary material).

\section{Gender wise prevalence:}

Gender wise prevalence of these three institutes showed that there were total 780 patients of district Bannu in which 368 (47.17\%) were male and $412(52.82 \%)$ were female. The rate of cancer incidence is high in female $52.82 \%$ then male $(47.17 \%)$ as shown in table No. 02 (supplementary material).

\section{Marital status wise prevalence:}

Those cancer patients who visited NORI, 24 (80\%) were married and 6 (20\%) were unmarried. Cancer patient who consulted NORI, IRNUM and SKMCH \& RC from district Bannu were 780, out of which 594 (76.15\%) were married, 185 (23.71\%) were unmarried and $01(0.12 \%)$ was widow. From these results it has been concluded that the cancer prevalence was high in married patients as shown in Table No. 03 (supplementary material).

\section{Addiction wise prevalence:}

There were no any data available for the patients of district Bannu from SKMCH \& RC for the prevalence of cancer in addicted patients. From the two institutes data results indicated that most of the cancer patients were addicted to smoking having 42 (6.04\%) patients followed by snuff addicted patients having 23 (3.30\%) patients out of total 695 patients. From these 205 (29.49\%) cancer patients were not addicted to any type of narcotic agents while the remaining $425(61.15 \%)$ patient's data were not reported. This data is shown in the form of Table no. 04.

Table No. 04: Addiction wise cancer prevalence in district Bannu from year 2005-2009

\begin{tabular}{|c|c|c|c|c|c|c|}
\hline $\begin{array}{l}\text { Total } \\
\text { patients }\end{array}$ & smoking & Percentage & Snuff & Percentage & Alcohol & Percentage \\
\hline 695 & 42 & $6.04 \%$ & 23 & $3.30 \%$ & 0 & $0 \%$ \\
\hline
\end{tabular}

\section{Cancer type wise prevalence}

From the 3 institutes collected data analysis for the type of cancer showed that high incidence rate was found in malignant tumor. Out of total 780 cancer patients, 114 (14.61\%) patients were benign cancer while the remaining $666(85.38 \%)$ patients were malignant type cancer which is shows in Table no. 05.

Table No. 05: Type wise cancer prevalence in district Bannu from year 20052009 


\begin{tabular}{|l|l|l|l|l|}
\hline $\begin{array}{l}\text { Total } \\
\text { patients }\end{array}$ & Benign & percentage & Malignant & percentage \\
\hline 780 & 114 & $14.61 \%$ & 666 & $85.38 \%$ \\
\hline
\end{tabular}

\section{Site wise cancer prevalence}

Combine results of the data which were collected on the basis of primary site affected were arranged conferring to the international organization of diseases, 9th revision, clinical. These data showed that in district Bannu, blood cancer was a leading cancer, 93 (11.92\%) patient followed by cancer of digestive system, $92(11.79 \%)$ patient. The digestive system site consists of esophagus, stomach, gallbladder, liver and intestine. The cancer of breast contributed $76(9.74 \%)$ patients, made a third position in primary site affected. The cancer of brain and other CNS system have $64(8.20 \%)$ made fourth position followed by cancer of respiratory system, $62(7.94 \%)$ and cancer of lymphatic \& hemopiotic system have 50 (6.41\%). Lymphatic and Hematopoietic site is consist of Hodgkin's lymphoma (HD), NonHodgkin's lymphoma (NHL), Myeloid leukemia (AML, CLL, CML, ALL) and multiple myeloma. The cancer of urinary system have 44 (5.64\%) and oral cavity have $42(5.38 \%)$ occupied the seventh and eight position followed by male genital organs (Prostate and testis) have 37 (4.74\%), female genital organ have 36 (4.61\%), exo/endocrine glands have $23(2.94 \%)$, bone have $22(2.82 \%)$, eye \& ear have $14(1.79 \%)$, skin have $10(1.28 \%)$, pancreas and soft tissue have $8(1.02 \%)$. There were $100(12.8 \%)$ other types of cancer which has been given in table and figure no. 02 (attached as supplementary material).

Table No. 06: Type wise cancer prevalence in district Bannu from year 2005-2009

\begin{tabular}{|l|l|l|l|}
\hline S. No & Sites & Total patients & percentage \\
\hline 1 & Blood cancer & 93 & $11.92 \%$ \\
\hline 2 & Digestive system & 92 & $11.79 \%$ \\
\hline 3 & Breast cancer & 76 & $9.74 \%$ \\
\hline 4 & Brain and other CNS & 64 & $8.20 \%$ \\
\hline 5 & Respiratory system & 62 & $7.94 \%$ \\
\hline 6 & LyM \& HeM system & 50 & $6.41 \%$ \\
\hline 7 & Urinary system & 44 & $5.64 \%$ \\
\hline 8 & Oral Cavity & 42 & $5.38 \%$ \\
\hline 9 & Male genital organs & 37 & $4.74 \%$ \\
\hline 10 & Female genital organs & 36 & $4.61 \%$ \\
\hline 11 & Exo/endocrine glands & 23 & $2.94 \%$ \\
\hline 12 & Bone & 22 & $2.82 \%$ \\
\hline 13 & Eye and ear & 14 & $1.79 \%$ \\
\hline
\end{tabular}




\begin{tabular}{|l|l|l|l|}
14 & Skin & 10 & $1.28 \%$ \\
\hline 15 & Pancreas and soft tissue & 8 & $1.02 \%$ \\
\hline 16 & Other & 100 & $12.80 \%$ \\
\hline
\end{tabular}

\section{Test performed}

Different tests are conducted for diagnosis of different types of cancer. When the collected data were analyzed for type of test performed in the two institutes for diagnosis of cancer, results showed that out of total 695 patients, mostly patients $670(96.40 \%)$ were diagnosed through biopsy followed by 506 (72.80\%) patients were through X-ray, $398(57.26 \%)$ patients through different blood tests, 29 (4.17\%) patients through CAT scan, 24 (3.45\%) patients through MRI and through endoscopy $5(0.71 \%)$ patients were diagnosed. In SKMCH \& RC the data of diagnostic tests for cancer was not recorded in the provided files. Mostly same patient were diagnosed through different diagnostic tests as given in Table No. 07 and in figure No.03(attached as supplementary material).

Table No. 7: Test performance based cancer prevalence in district Bannu from year 2005-2009

\begin{tabular}{|l|l|l|l|}
\hline S. No & Tests & Patients & percentage \\
\hline 1 & Biopsy & 670 & $96.40 \%$ \\
\hline 2 & X-rays & 506 & $72.80 \%$ \\
\hline 3 & Blood & 398 & $57.26 \%$ \\
\hline 4 & CAT scan & 29 & $4.17 \%$ \\
\hline 5 & MRI & 24 & $3.45 \%$ \\
\hline 6 & Endoscopy & 5 & $0.71 \%$ \\
\hline
\end{tabular}

\section{Discussion}

The descriptive statistical analysis of data collected from three different Institutes shows the annual prevalence rate in districts Bannu and information regarding the most infected person especially age wise, gender wise, marital status based, addiction based, types of cancer, most affected site wise and test performed for diagnosis. The data also represents the information about the expected annual increase in cancer prevalence.

Total 780 cancer patients were registered into three above mention institutes. An average prevalence per year has been determined for each institute; 0.88 in Nuclear Medicine Oncology and Radiotherapy Institute (NORI) Islamabad, 19.63 in Institute of Radiotherapy and Nuclear Medicine (IRNUM) Peshawar and 2.5 in Shukat Khanum Memorial Cancer Hospital and Research Center (SKMCH\&RC) Lahore.

Percentage prevalence has been calculated for each year. Increase prevalence per year has been found in IRNUM as compared to rest of institutes. The reason may be easy accessibility to this institute as compared to other. The average annual prevalence in all 
these institutes for cancer in district Bannu has been calculated as 7.67, which is an alarming. Zeb et al. (2006) had reported a high prevalence (15.6) of cancer at District Dir (Lower). Ali et al. (2009) also studied prevalence of esophageal carcinoma in different sex and age group in the Northern area of Pakistan. Bhurgri et al. (2007) also reported the prevalence rate of breast cancer (30.9) in the female population of Karachi South, during 1995-1997. The decrease in prevalence rate is due to area difference and awareness about cancer among people of District Bannu. Combine collected data were evaluated for the age wise distribution and concluded that mostly affected cancer patients were that of age group of 51-60 years having $172(22.05 \%)$ patients followed by patients of age group of 41-50 years having $152(19.48 \%)$ and the patients were less affected in age group of 70-80 years and 80 plus having $28(3.58 \%)$ and $11(1.14 \%)$ respectively. The present results shows similarities with Jamal et al. (2006), who determined that peak prevalence were in the 50 60 year age group. Zeb et al. (2006), studying age wise cancer prevalence, found that the highest rate was the cancer of all sites was among the age group of 41-50 and lowest prevalence rate was among the age group of 71-80 years. Same study made by (Ahmad et al., 2007) which shows that mean age for all skin cancers considered together was 58.75+/15.21. Bhurgri et al. (2005) stated that all sites cancer with age of both male and female were 45.2 years. The reason might be that in aged people there is a great chance of mutation because the activity of immune system decreases. The rate of cancer prevalence is high in female $52.82 \%$ then male $(47.17 \%)$. These finding correlates with the study of Bhurgri et al. (2004), that mentions a high ratio of cancer in female (47.6\%) than men (13\%). Another study of Burgri et al. (2005) concluded that in Hyderabad the age standardized rates for cancer both in male and female were 91.6 and 96.0 respectively. The present results are not in co-relation with the studies of Khan et al. (1997), Alidina et al. (2004) and Zeb et al. (2006), who analyzed the frequency of cancer and mentioned that male were more affected than female. The probable reason is that in district Bannu, female is responsible for most of the activities either outside the home or inside. They used to do work in the fields according to their culture and society. They are most at risk to environmental factors than male. Cancer prevalence rate was high in married patients 594 (76.15\%) than unmarried patients $185(23.71 \%)$ Our study shows contrast with the study performed in other countries which shows high prevalence of cancer in unmarried peoples as stated by James et al., (1987), that unmarried persons still had poorer survival and high rate of cancer prevalence. Cancer patients were addicted to smoking having 42 (5.38\%) followed by snuff addicted patients having 23 (2.94\%). The same study was conducted by Bhughri et al. (2005), and mentioned that cancer types which are tobacco associated were accountable $40 \%$ males and $20 \%$ in females for approximately. These results are in agreements with our study. High prevalence rate of malignancy was found which have been supported by Alam at al. (2001), compared world prevalence of ovarian tumor whether benign or malignant with that of local area (Abbotabad). Ahmad et al. (1991) also presented a study of 14,018 malignant tumors from Northern Pakistan. Blood cancer was a leading cancer 
followed by cancer of digestive system, breast, brain, respiratory system, lymphatic \& hemopiotic system, urinary system, oral cavity and male/ female genital organ. Related results to present study have mentioned by Khan et al. (1997), that analyzed that the reported cancer in female was breast cancer. Our results are also in-correlation with Bhurgri et al. (2002). Jamal et al. (2006) has mentioned 10.8\% GIT malignancies in Northern Pakistan. Skin cancer prevalence reported by Ahmad et al. (2007). Baig and Ali, (2006) have also mentioned that breast cancer is the most prevalent cancer among female. And mostly cancer patients in the selected institutes were mostly diagnosed through biopsy followed by X-ray, different blood tests, CAT scan, MRI and endoscopy. These tests are most authentic and accurate for diagnosis of various types of cancer.

\section{Conclusion:}

From the present study it has been concluded that there is heavy burden of cancer in district Bannu. Female are more affected than male. Most of the female are left undiagnosed/untreated due to their social, economic, religious and customary matters. There must be proper checkup of female as healthy female contributes well in a healthy society. Cancer registry institutes playing a major role in registration, diagnosing and treating cancer patients throughout Pakistan. The cancerous patients need more care and proper treatment to whom, these cancer registry institutes giving a proper concentration and emphasis is usually given on proper diagnosis and treatment. The results also reveal that sophisticated facilities/staff are available at these institutes.

\section{Recommendations:}

Degular screening must me there and people should be guided about the early signs $\&$ symptoms of cancer, so if cancer does exit it will diagnosed in early stage when it is most responsive to treatment.

> Positive changes in habits and routine are strongly recommended for the prevention of cancer because most of the causation factors of cancer can be controlled by healthy life style choices.

$>$ Proper care of health should be taken as people having immune system diseases are more susceptible to cancer.

$>$ Cigarettes and other tobacco products like pipes snuff and chewing tobacco, which are linked to lungs and oral cavity cancer must be avoided.

Media would show its vital role in awareness of society about the cancer.

$>$ Medical societies and universities should arrange seminars and awareness programs about the cancer.

$>$ Ministry of health should conduct survey and mass screening after regular intervals, so that it may know the status of cancer among of the people and also it should have up to date information about prevalence and prevalence of cancer. 


\section{References:}

Abbas F, (2003). Pakistan to be worst hit country with high prevalence of cancer cases by 2015. Pakistan Press International.

Ahmad M, Khan A. H, Mansoor A, (1991). The pattern of malignant tumors in Northern Pakistan. J Pale Med Assoc, 41: 70-3.

Ahmed A, Alam M. B, Khan W, et al (2007). Frequency and Characteristics of Skin Cancers Diagnosed at Ayub Medical College Abbottabad Pakistan from 1995-2003. J of Ayub Med Coll Abottabad, 19(4): 3-6.

Alam I, Waqar F, Khan A, (2001). Prevalence and management of ovarian tumors in Women and Children Hospital Abbottabad. J Ayub Med Coll Abbottabad, 13(2): 19-21.

Ali A, Naseem, M, Khan, T. M. (2009). Oesophageal cancer in northern areas of Pakistan. J Ayub Med Coll Abbottabad, 21(2): 148-50.

Alidina A, Gaffar A, Hussain F, et al (2004). Survival data and prognostic factors seen in Pakistani patients with esophageal cancer. Ann Oncol, 15(1): 118-22.

Apantaku L M, (2000). Breast Cancer Diagnosis and Screening. American Family Physician, 62(3): 596-602.

Baig S, Ali T. S, (2006). Evaluation of Efficacy of Self Breast Examination for Breast Cancer Prevention: a Cost Effective Screening Tool. Asian Pacific J Cancer Prev, 7: 154156.

Bhurgri A, Bhurgri H, Shah A, et al (2003). Prevalence of cancer of the esophagus in Quetta and Karachi, Pakistan. Indian J Gastroenterol, 22: 170-2.

Bhurgri Y, (2004). Karachi Cancer Registry Data - Implications for the National Cancer Control Program of Pakistan. Asian Pac J of Cancer Prev, 5(1): 77-82.

Bhurgri Y, Bhurgri A, S Pervez, et al (2005). cancer profile of Hyderabad, Pakistan 19982002. Asian Pac J of Cancer Prev, 6(4): 474-80.

Bhurgri, Y, Bhurgri A, Shah H, et al (2002). Prevalence of cancer esophagus in Quetta and Karachi, Pakistan. Indian J of Gastroenterol, 22(5): 170-172.

Bhurgri, Y, Kayani N, Faridi N, et al (2007). Patho-epidemiology of breast cancer in Karachi '1995-1997. Asian Pac J Cancer Prev, 8(2): 215-20.

Cancer Facts and Figures, (2003). American Cancer Society, Inc. surveillance Research.

Cancer Research Uk. (2005).

Doll R, Peto R, (1987). In Oxford Textbook of Medicine. Ed 2 ${ }^{\text {nd }}$. Epidermology of cancer. Oxford University press, Oxford, UK pp 4.95-4.123.

Elmore G J, Armstrong K, Lehman C D, et al (2005). Screening for Breast Cancer. J of 
American Med Association, 293(10): 1245-1256.

Gress D M, (2002). Your cancer registry: more than just case counts. Oncol Issues, 17: 28-31

International Atomic Energy Agency, (2003). Method for Developing Arrangements for Response to a Nuclear or Radiological Emergency: Updating IAEA-TECDOC-953, EPRMETHOD 2003, IAEA, Vienna.

Jamal S, Mamoon, N, Mushtaq S, et al (2006). Carcinoma of the Male Breast A Study of 141 Cases from Northern Pakistan. Asian Pac J of Cancer Prev, 7(1): 119-121.

Javed A A, (2006). Progress of Oncology in Pakistan. Indian J of Med \& Paediatric Oncology, 27(3): 54-59.

Kardinal, C, Yarbro, (1979). A conceptional histroy of cancer. Semin Oncol, 6: 396-408.

Karnofsky D A, (2010). Chemotherapy of Cancer. CA Cancer J Clin, 5: 165-173.

Karp G, (1996). Cell and Molecular biology. Ed $1^{\text {st }}$. Canada: John Wiley and sons, Inc pp 694-695.

Khan H, Khawaja M I, Khawaja M R, (2006). Dilemma of Cancer Screening in Pakistan. Asian Pac J of Cancer Prev, 7: 340-341.

Khan S M, Gillani J, Nasreen S, et al (1997). Pediatric Tumors in North West Pakistan and Afghan Refugees. Pediatric Hematol \& Oncol, 14(3): 267-272.

Khan S M, Gillani, J, Nasreen S, et al (1997). Cancer in North West Pakistan and Afghan refugees. J of Pak Med Asso, 47(4): 122-4.

Kumar V, Cottran R S, Robins S L, (1989). Pathological basis of disease. Ed $4^{\text {th }}$. Philadelphia: Saunders Company pp 239-305.

Miller A B, Hoogstraten B, Staquet M, et al (1981). Reporting Results of Cancer Treatment. Cancer, 47: 207-214.

$\mathrm{Ng} \mathrm{N}$, Minh H V, Tesfaye F, et al (2005). Combining risk factor and demographic surveillance - potentials of WHO STEPS and DSS methodologies for assessing epidemiologic transition. Scand J Public Health, In press.

Oldham R K, (1987). Principle of Cancer Biotherapy. Ed $2^{\text {nd }}$. Raven Press New York pp 23-53.

Park K, (2002). Preventive and Social Medicine, Ed 22 ${ }^{\text {nd }}$. Pp 547.

Parveen S, Ilyas N, Asghar S, et al (1999). Patterns of care for ovarian cancer: Patients at Institute of Nuclear Medicine and Oncology (INMOL) Lahore. Specialist J Pak Med. Sci, 15: 209-15 
Rojas A, (2002). Cancers: Actions I can Take to Reduce My Risks of Developing Cancer. ISBN \#1-894396-38-3.

Takalkar A M, Haddad G E, Lilien D L, (2008). FDG- PET and PET/CT. Indian J of Radiology Imaging, 18(1): 17-36.

Zeb A, Rasool A, Nasreen S, (2006). Occupation and Cancer Incidence in District Dir (NWFP), Pakistan (2000-2004). Asian Pac J of Cancer Prevention, 7: 483-484. 